\title{
The airway vasculature: recent advances and clinical implications
}

\author{
P Paredi, P J Barnes
}

National Heart and Lung Institute, Imperial College London, London, UK

Correspondence to: Dr P Paredi, National Heart and Lung Institute, Airway Disease Section, Dovehouse Street, London SW3 6LY, UK p.paredi@ic.ac.uk

Received 4 April 2008 Accepted 29 July 2008

\section{ABSTRACT}

It is increasingly recognised that the airway circulation plays an important role in airway diseases, either through a change in blood flow or through microvascular leakage. Most of the information available regarding the anatomy and physiology of bronchial blood flow and its regulation has necessarily derived from animal studies. However, there have recently been important advances in understanding airway blood flow in airway disease in humans through the development of non-invasive methods and in the quantification of microvascular leakage using plasma markers. These studies have shown that bronchial blood flow is increased in patients with asthma but not in those with chronic obstructive pulmonary disease, confirming previous pathology investigations. Changes in bronchial blood flow may in part reflect the generation of new vascular vessels, a process known as "angiogenesis" which is caused by airway inflammation. Angiogenesis and the resulting plasma leak affect airway physiology, drug clearance and its bioavailability. This review discusses the anatomy, physiology and regulation of bronchial blood flow in the normal and diseased lung, In addition, it analyses the effect of current medical treatment and discusses the potential use of new antiangiogenesis medications. The development of noninvasive assessment of bronchial blood flow and the study of angiogenesis have provided a tool to investigate airway physiology in vivo; these advances will contribute to a better understanding of inflammatory airway diseases as well as the implication of these findings to management.

\section{ANATOMY OF THE BRONCHIAL CIRCULATION}

The pulmonary circulation is a high-capacitance low-resistance network of vessels which accommodates the entire venous return of the body, whereas the bronchial circulation is a high-resistance low-capacitance circulation which receives only $1-2 \%$ of the total cardiac output in normal subjects. ${ }^{1}$

\section{Bronchial arteries}

The bronchial circulation is part of the systemic circulation. Normally there are two main bronchial arteries, at least one of which originates from the aorta and the other from the intercostal arteries or, very rarely, from the internal mammary and the coronary arteries. The bronchial arteries join the main bronchi at the hila where they divide into two or three branches that wind around and supply the wall of the bronchus. These arteries divide into smaller vessels that anastomose and form a peribronchial arterial bronchial plexus (fig 1). They also give rise to small arterioles that penetrate the muscular layer to reach the bronchial mucosa where they form the submucosal plexus. The bronchial arteries also supply the visceral pleura.

\section{Bronchopulmonary circulation}

About two-thirds of the bronchial capillary blood is thought to drain into anastomoses or communicating vessels that empty into the pulmonary veins forming the so-called "bronchopulmonary circulation".

\section{Bronchial veins}

The bronchial submucosal and adventitial venules drain into the bronchial veins which drain into the azygos and hemiazygos veins. ${ }^{2}$ However, the intrapulmonary bronchial circulation mostly drains directly into the pulmonary circulation through bronchopulmonary anastomoses.

\section{PHYSIOLOGY OF THE BRONCHIAL CIRCULATION}

Most studies on the physiology of bronchial blood flow have been carried out on animals; this is a major limitation and unfortunately we can only assume that there are similarities with humans.

\section{Oxygenation}

Contrary to what has been shown for the pulmonary circulation, systemic hypoxaemia increases both anastomotic and total bronchial blood flow.

\section{Inhaled air temperature}

The inhalation of cold air caused an immediate increase of the bronchial blood flow in an animal study. ${ }^{3}$ However, data in humans are scarce and unreliable.

\section{Positive end expiratory pressure}

The alveolar pressure and the lung volume significantly affect the bronchial blood flow with higher airway pressures decreasing blood flow. ${ }^{1}$ This may be due to mechanical compression of the blood vessels.

\section{Pulmonary and systemic artery pressure}

There is an inverse relationship between pulmonary artery pressure and the pressure in the left atrium and bronchial blood flow. On the contrary, elevated systemic blood pressure is associated with an increase in bronchial blood flow. ${ }^{1}$

\section{Neurological regulation}

The bronchial arteries have $\alpha$ - and $\beta$-adrenergic receptors and it is known that adrenaline, which 


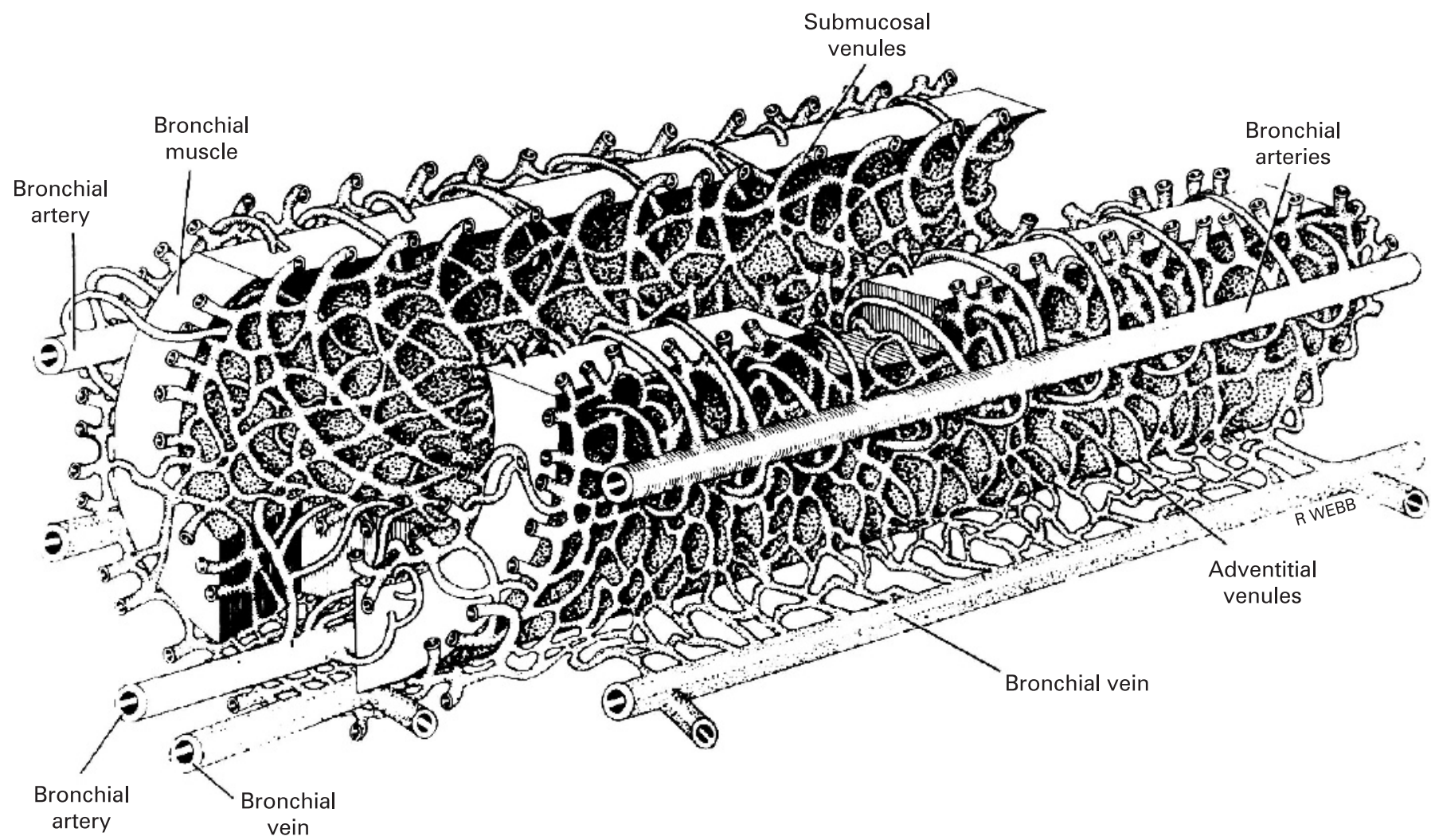

Figure 1 Schematic representation of the bronchial circulation illustrating the adventitial and submucosal plexuses. Reproduced with permission from Deffebach et al. ${ }^{1}$

has $\alpha$-agonist effects, reduces total bronchial flow as it does in other systemic vascular beds. ${ }^{4}$

Even though the action of the parasympathetic system on the bronchial blood flow is controversial, there are indications that the stimulation of the vagus increases total bronchial flow. ${ }^{1}$

Animal studies show that several peptides released from airway nerves, such as vasoactive intestinal peptide from cholinergic nerves and substance $\mathrm{P}$ and calcitonin gene-related peptide, are potent bronchial vasodilators and may also increase microvascular leak.

\section{Effect of mediators}

Histamine

Histamine causes vasoconstriction of the pulmonary circulation and vasodilation of the systemic vascular bed. ${ }^{6}$ In the bronchial circulation, histamine inhalation causes an increase in blood flow which is mediated via $\mathrm{H}_{2}$-receptors. ${ }^{7}$

Prostaglandins (PGs)

$\mathrm{PGF}_{2 \alpha}$ has been shown to increase bronchial blood flow. ${ }^{8}$ Cyclooxygenase inhibitors reduce the increase in bronchial blood flow resulting from hypoxia. ${ }^{9}$

\section{Nitric oxide}

Sasaki et al showed that the administration of $\mathrm{N}^{\mathrm{G}}$-nitro-Larginine (L-NNA), a competitive inhibitor of $\mathrm{NO}$ synthase, decreased bronchial blood flow and inhibited acetylcholineinduced vasodilation. ${ }^{10}$ The administration of exogenous inhaled $\mathrm{NO}$ resulted in a dose- dependent increase in bronchial blood flow and a decrease in vascular resistance in sheep. ${ }^{11}$

\section{FUNCTION OF THE BRONCHIAL CIRCULATION \\ Airway nutrition}

The bronchial circulation provides nourishment to the airways. However, an acute obstruction of the main bronchial artery does not cause ischaemic changes; this may be due to a retrograde blood flow through the bronchopulmonary anastomoses.

\section{Airway lining fluid and local defences}

The bronchial circulation is responsible for the formation of the epithelial lining fluid which plays a role in the local defences against inhaled irritations and substances. A functional bronchial circulation is required for the maintenance of normal mucociliary transport. ${ }^{1}$

\section{Clearance of small particles}

Interrupting bronchial artery perfusion in sheep resulted both in increased retention of a soluble tracer at the site of deposition and attenuation of the uptake of ${ }^{99 \mathrm{~m}} \mathrm{Tc}$-DTPA into the bronchial circulation. ${ }^{12}$ This indicates that bronchial blood flow is essential for the absorption and distribution of the particles and their clearance.

\section{Airway temperature and air conditioning}

The airway mucosa responds to the cooling of the airways following the inhalation of cold air by increasing bronchial blood flow and therefore improving heat and moisture transfer. ${ }^{1}$ This is a defence mechanism to protect the mucosa from "cold friction burns". When the inhaled air temperature is elevated and dry, the respiratory system conserves the fluids by exhalation of practically dry air, losing only one-tenth of the water previously used to humidify the air inhaled. 


\section{MEASUREMENT OF BRONCHIAL BLOOD FLOW}

Several techniques have been developed to measure bronchial blood flow invasively in animals. Bronchial blood flow has recently been measured non-invasively in humans and has been suggested as a marker of airway inflammation in asthma and chronic obstructive pulmonary disease (COPD). ${ }^{13}{ }^{14}$

\section{Invasive measurement of bronchial blood flow}

The total bronchial blood flow can be measured by dissecting and isolating the bronchial vessels separately. Less invasive methods are dye video densitometry and the use of radioactive microspheres where blood flow is estimated from the radioactivity found in the excised lung. ${ }^{1}$

\section{Non-invasive measurement of blood flow \\ Dimethylether method}

The lung uptake of soluble inert gases is used to measure pulmonary blood flow as an index of cardiac output. The same principle was applied to measure the blood flow of the airways ${ }^{15}$ making use of dimethylether (DME), a soluble gas with a high affinity for haemoglobin. This method is based on the assumption that the uptake of an inert soluble gas in a tissue with capillaries and active flow of blood is determined by the volume of the tissue and by the blood flow. ${ }^{16}$ The same method was later modified and validated indirectly with microspheres in sheep. ${ }^{17}$

The DME method requires multiple breath holds followed by exhalations into a spirometer. The concentrations of DME, nitrogen and helium are measured at the airway opening with a mass spectrometer. ${ }^{18}$ This method has not been used in laboratories other than the one where it was first developed. This may in part be due to its complexity; eight breath hold manoeuvres are required for a single measurement. To address these limitations, the same group that developed the method originally has recently simplified the technique by reducing the number of breath holds to two. ${ }^{19}$

\section{Acetylene method}

Acetylene, like DME, has a very high affinity for haemoglobin but is less explosive. ${ }^{20}{ }^{21}$ Subjects inhale a gas mixture which includes acetylene $5 \%$ and exhale into a mass spectrometer. The area under the curve (AUC) of the acetylene tracing is inversely proportional to bronchial blood flow, so multiple breath holds are not required.

The effect of vasoactive compounds such as the vasoconstriction induced by corticosteroids, ${ }^{14}$ adrenaline ${ }^{22}$ and L-NAME ${ }^{22}$ and the vasodilation following the inhalation of $\beta_{2}$-agonists $^{13} 1422$ and nitric oxide $(\mathrm{NO})^{22}$ support the hypothesis that the method effectively measures bronchial blood flow. The same method has been developed independently by two groups.

\section{ANGIOGENESIS IN AIRWAY DISEASE}

Inflammation is associated with the generation of new blood vessels (angiogenesis).

\section{Role of VEGF and other angiogenic mediators}

Angiogenesis has been extensively studied and the vascular endothelial growth factor (VEGF) has received increasing interest because of its role, not only in angiogenesis, but also in the regulation of vascular permeability and lung development. The VEGF family signals through three different receptors. Even though VEGF-A also binds to VEGFR-1, VEGFR-2 has been shown to account for most of its effects. ${ }^{23}$ Besides being a vascular endothelial mitogen for arteries, veins and lymphatics, VEGF promotes endothelial survival by inducing the expression of the anti-apoptotic proteins BCL-2 and $\mathrm{A} 1 .{ }^{24} \mathrm{VEGF}$ also regulates capillary permeability by inducing the fenestration in endothelial cells. ${ }^{25}$

Hypoxia ${ }^{26}$ and cytokines such as interleukin(IL)-1 $\alpha$ and IL6 increase the expression of VEGF, but IL10 and IL13 downregulate its expression. Lung disorders characterised by inflammation and/or hypoxia such asthma and COPD therefore show pathological levels of VEGF.

Patients with asthma have increased concentrations of VEGF in induced sputum $^{27}$ and BAL fluid ${ }^{28}$ which are negatively correlated with airway obstruction and positively correlated with eosinophilic inflammation and vascular permeability. ${ }^{29}$

The role of VEGF in COPD is unclear. The concentration of VEGF may be reduced in the induced sputum of patients with emphysema but raised in subjects with chronic bronchitis. ${ }^{30}$

VEGF works in concert with other growth factors including angiopoietins. Four members of the angiopoietin family are now known and angiopoietin-1 (Ang-1) has received a lot of interest and promotes circumferential growth. ${ }^{31}$
Figure 2 Bronchial biopsy sections from (A) and (C) a child with asthma and (B) and (D) a control child showing increased number of subepithelial vessels ( $A$, brown) and eosinophils $(C$, red) in the child with asthma. Arrows indicate epithelial loss ( $A$ and $C$ ) whereas arrowheads indicate reticular basement membrane thickening $(A)$. Immunostaining with monoclonal antibody anti-CD31 ( $A$ and $B$ ) and antiEG2 (C and D). Original magnification $\times 630$. Reproduced with permission from Barbato et al. ${ }^{37}$
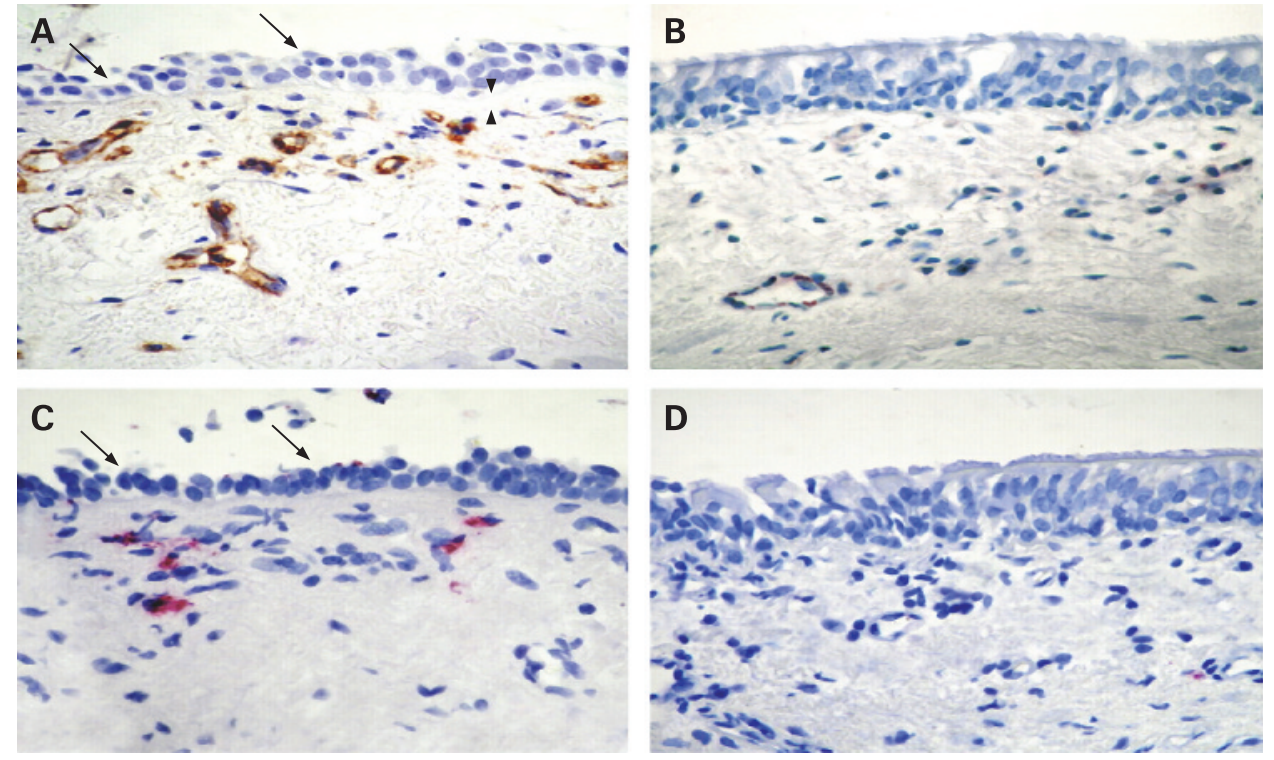
Even though VEGF is considered the main angiogenic factor, other molecules have been investigated including fibroblast growth factor (FGF), ${ }^{29}$ angiogenin, ${ }^{29}$ tumour necrosis factor- $\alpha$ $(\mathrm{TNF} \alpha)^{32}$ and chemokines such as IL8 and eotaxin, all of which may have a role in lung angiogenesis.

\section{Angiogenesis}

The term "angiogenesis" defines the expansion of the primitive capillary vascular bed into a more complex network. ${ }^{33}$ Angiogenesis starts with vasodilation, which requires $\mathrm{NO}$. Vascular permeability increases in response to VEGF, allowing extravasation of plasma proteins that lay down the provisional scaffolding for migrating endothelial cells. Contrary to the action of VEGF, Ang-1 inhibits vascular permeability without affecting vascular morphology. Endothelial cells need to loosen interendothelial cell contacts to emigrate from their resident sites. Ang-2, an inhibitor of endothelial-specific tyrosine kinase (Tie-2) signalling, may be involved in detaching smooth muscle cells and loosening the matrix. Once the intracellular contacts have been loosened, VEGF initiates endothelial network organisation and Ang-1 stabilises the newly formed vessels.

\section{BRONCHIAL VESSELS IN AIRWAY DISEASE}

\section{Asthma}

The bronchial submucosa of patients with asthma has an increased number of vessels, occupying a larger percentage of area than in normal subjects ${ }^{29}{ }^{34}$ - not only in the large but also in the medium and small airways. ${ }^{35}$ These changes are also present in patients with mild and moderate disease ${ }^{36}$ and in children (fig 2). ${ }^{37}$ The use of a high magnification bronchovideoscope has recently allowed direct visualisation of the bronchial vessels, ${ }^{38}$ confirming the presence of an increased number of vessels in subjects with asthma (fig 3).

Airway vascular remodelling and inflammation may be responsible for increased bronchial blood flow ${ }^{39}$ and exhaled breath temperature gradients in patients with asthma. ${ }^{40}$ The measurement of bronchial blood flow may indirectly reflect airway inflammation and angiogenesis. Besides being increased in asthma as expected, ${ }^{14}{ }^{39}$ bronchial blood flow is also correlated with the concentrations of exhaled $\mathrm{NO},{ }^{14}$ a potent vasodilator and a marker of inflammation. Subjects with asthma also show increased heat exchange and airway temperature gradients $\left(\Delta \mathrm{e}^{\circ} \mathrm{T}\right)$ which correlate with bronchial blood flow and exhaled $\mathrm{NO}$. Increased levels of $\mathrm{NO}$ may lead to vasodilation and increased bronchial blood flow, as shown by the correlation between exhaled $\mathrm{NO}$ and $\Delta \mathrm{e}^{\circ} \mathrm{T}$ (fig 4).

\section{COPD}

Early histological studies showed decreased bronchial vascularity in patients with COPD. ${ }^{41}{ }^{42}$ More recently, some authors have confirmed that the number of vessels in the airways of these patients is not significantly increased. ${ }^{35}$ A bronchovideoscopic study ${ }^{38}$ and the measurement of bronchial blood flow ${ }^{13}$ also support the hypothesis that vascular remodelling is not a feature of COPD airways (fig 3). However, at least two studies have shown increased bronchial vascularity. ${ }^{43} 44$ This discrepancy may be due to the recruitment of more severe and elderly patients in the last two studies.

In keeping with the studies showing increased vascularity of the airways, VEGF levels are increased in the induced sputum of patients with chronic bronchitis and the expression of VEGF in central and peripheral airways of ex-smokers with COPD is higher than in a normal control group. ${ }^{45}$ VEGF expression is correlated
Figure 3 Bronchovideoscopic images of the lower trachea of a control subject, a patient with chronic obstructive pulmonary disease (COPD), a steroidnaive patient with newly diagnosed stable asthma (ICS $(-))$ and a patient who has had stable asthma for more than 5 years treated with inhaled corticosteroid (ICS $(+))$. Airway vascularity is increased in the patients with asthma compared with the control subject and the patient with COPD. Reproduced with permission from Tanaka et al. ${ }^{38}$
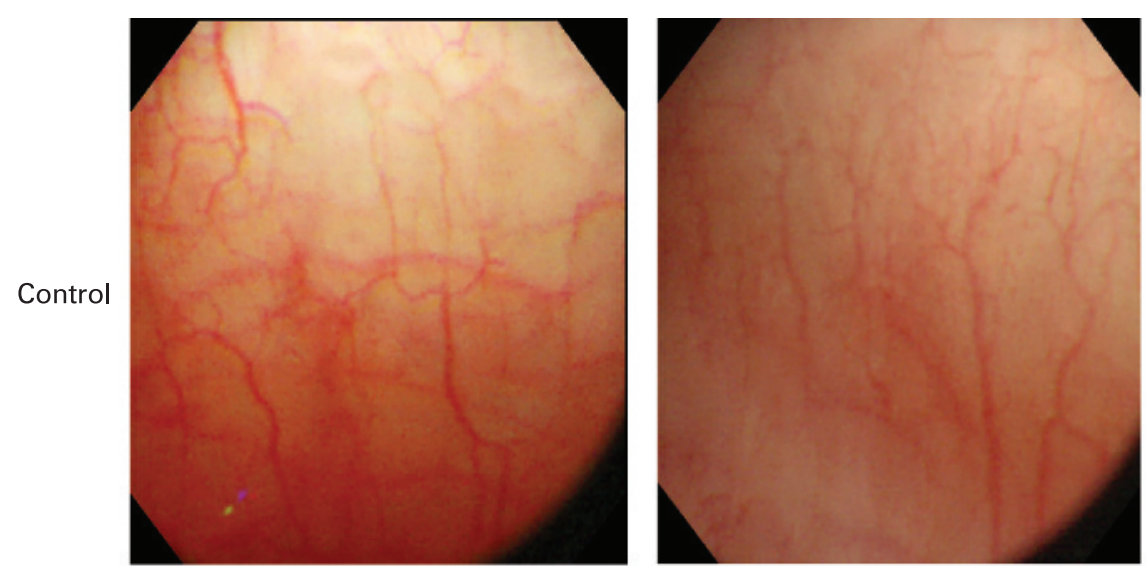

COPD
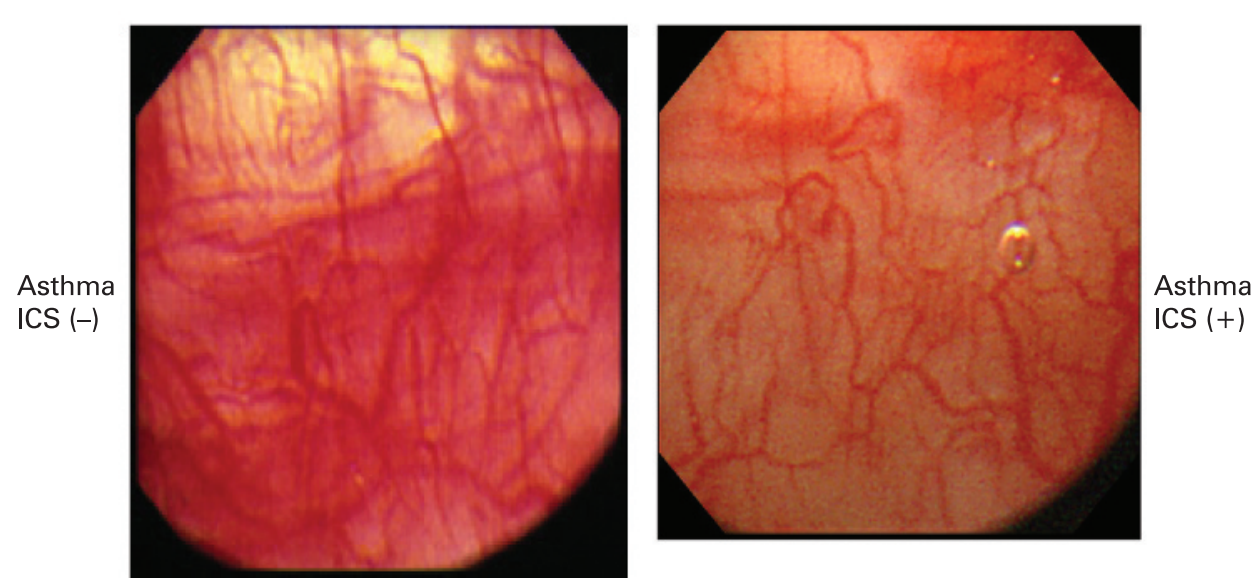


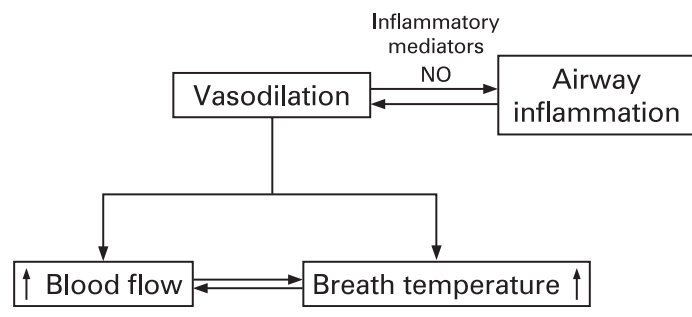

Figure 4 Schematic representation of the interaction between inflammation, bronchial blood flow and exhaled breath temperature.

with airflow obstruction and inflammatory cytokines such IL8 and TNF $\alpha$ and has been suggested as a marker of inflammation. ${ }^{46}$

However, the role of VEGF in the pathogenesis of COPD is twofold; it may be detrimental in the bronchi where it correlates with obstruction and protective in the alveoli where lower levels of VEGF correlate with alveolar destruction. ${ }^{30}{ }^{47}$ The decrease in VEGF in the lower respiratory tract ${ }^{48}$ may lead to the development of emphysema. This hypothesis is also supported by in vitro and in vivo studies showing that reduced VEGF levels or blockade of VEGF receptors could play a role in the pathogenesis of emphysema. ${ }^{49}$

\section{Bronchiectasis}

Liebow $^{50}$ in 1949 showed enlargement of the bronchial arteries and increased anastomoses with the pulmonary circulation. A similar pattern was described in tuberculosis where the affected areas present increased bronchial blood flow and dilation and proliferation of the bronchial capillaries ${ }^{51}$ and bronchopulmonary anastomoses. These can form small pedunculated aneurysms found inside the tuberculous cavities, as described originally by Rasmussen, the rupture of which results in haemoptysis.

\section{AIRWAY MICROVASCULAR LEAKAGE}

\section{Mechanisms}

VEGF stimulates the formation of new vessels with increased permeability ${ }^{52}$ which cause mucosal oedema and reduce airway diameter (fig 5). Two endothelial-specific tyrosine kinase (Tie) receptors have been described, Tie- 1 and Tie- $2 .^{53}$ Tie-2 is highly expressed in the lung. Both Ang-1 and Ang-2 bind to Tie-2 receptors with equal affinity, but they have opposite effects. Ang-1 reduces the permeability of the vessels ${ }^{31}$ whereas Ang-2, which is a competitive antagonist of Ang-1 on Tie-2 receptors, increases vascular permeability.

As well as redness due to increased blood flow ("rubor"), tissue swelling ("tumour") is also a cardinal sign of inflammation. Microvascular leakage and plasma exudation are seen in both asthma and COPD as signs of airway inflammation, and many mediators may produce this effect by relaxing postcapillary venular endothelial cells, including mediators of inflammation such as histamine, cysteinyl-leukotrienes, bradykinin, platelet-activating factor and adenosine as well as neuropeptides such as substance P. Bronchial vasodilators increase plasma exudation by increasing the blood flow to leaky vessels and many mediators act as both vasodilators and induce leakage. Most of our knowledge of microvascular leakage is from studies in animals using Evans blue dye which binds to plasma proteins, but these methods are not applicable in humans. ${ }^{54}$ However, plasma exudation can be measured by assaying plasma proteins such as albumin. $\alpha_{2}$-Macroglobulin and fibrinogen in induced sputum or BAL fluid show an increased sputum/BAL concentration compared with plasma.

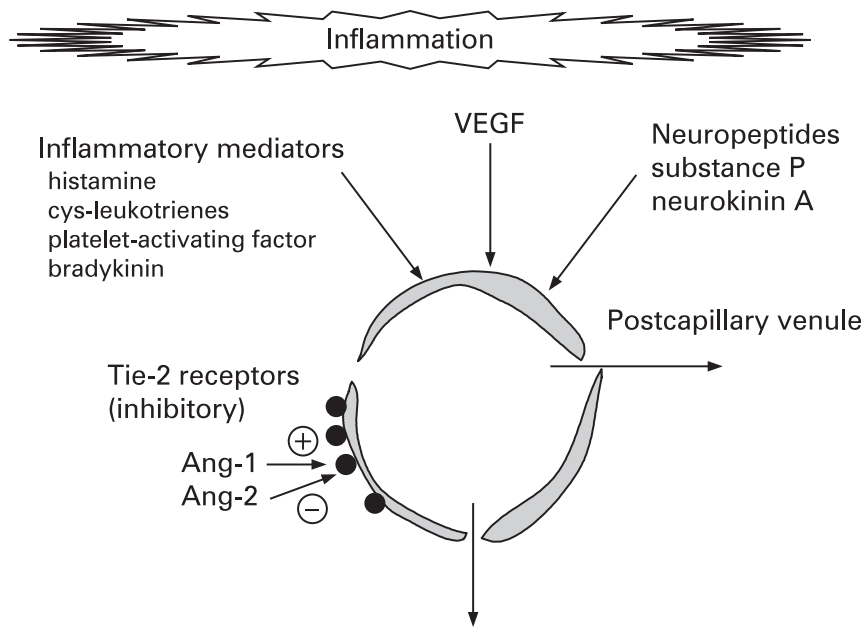

Albumin, $\alpha 2$-macroglobulin, fibrinogen

Oedema

Figure 5 Schematic representation of airway microvascular leakage. Inflammatory cytokines, vascular endothelial growth factor (VEGF) and neuropetides cause vascular leakage. Angiopoietin-1 (Ang-1) and angiopoietin-2 (Ang-2) bind to endothelial-specific tyrosine kinase-2 (Tie2) receptors with opposite effects. The measurement of albumin, $\alpha_{2}-$ macroglobulin and fibrinogen in the bronchoalveolar lavage fluid provides an estimate of the leakage.

\section{Measurement}

The permeability of the blood-airway lumen barrier can be measured by analysing albumin and $\alpha_{2}$-macroglobulin in BAL fluid and paired serum samples. ${ }^{55}$ However, because the epithelial lining fluid (ELF) may present different degrees of dilution during lavage, urea is measured as a marker of dilution. ${ }^{56}$

The vascular permeability has also been assessed by measuring the ratio of albumin concentrations in induced sputum and serum. ${ }^{57} 58$

\section{Asthma}

In patients with stable asthma there is an increase in plasma exudation into the airways which correlates with bronchial hyperreactivity to histamine. ${ }^{59}$ VEGF, Ang-1 and Ang-2 levels in induced sputum from patients with asthma are higher than those from normal control subjects and there is an inverse correlation between Ang-1 and the airway vascular permeability index. In contrast, Ang-2 is positively correlated with airway vascular permeability. ${ }^{57}$

\section{COPD}

In patients with COPD there in an increase in the sputum Ang2 level, particularly during infective exacerbations. The increased concentrations of VEGF in the airways of patients with a preponderant bronchiti ${ }^{60}$ may increase the permeability of the bronchial vasculature and facilitate oedema. This may explain the correlation between VEGF sputum levels and the degree of airflow obstruction. ${ }^{46}$

\section{EFFECT OF DRUGS}

\section{$\beta_{2}$-Adrenoceptor agonists}

A placebo-controlled study showed a significant decrease in the number of vessels $/ \mathrm{mm}^{2}$ in the lamina propria of patients with asthma following 3 months of treatment with salmeterol. ${ }^{61}$ 
This may have been caused by reduced levels of the angiogenic cytokine ${ }^{62}$ IL8 following salmeterol treatment. ${ }^{63}$

The long-term effect of $\beta_{2}$ agonists on the bronchial vasculature of patients with COPD has not yet been investigated, but their acute effect on bronchial blood flow $\left(\mathrm{Q}_{\mathrm{AW}}\right)$ is known. Like temperature gradients $\left(\Delta \mathrm{e}^{\circ} \mathrm{T}\right),{ }^{14} \mathrm{Q}_{\mathrm{AW}}$ is also increased in steroid-naïve patients with COPD after inhalation of salbutamol, a known bronchial vasodilator. ${ }^{39}$ This differs from the findings in asthma where inhalation of salbutamol does not affect $\Delta e^{\circ} \mathrm{T}$ or $\mathrm{Q}_{\mathrm{AW}}{ }^{14}$ probably because in asthma the vessels are already maximally dilated by inflammatory mediators. The finding of a lower $Q_{A W}$ increase after $\beta_{2}$ agonists in patients with COPD than in normal subjects supports the hypothesis that steroid-naïve patients with COPD have blunted vasoreactivity. ${ }^{64}$

Besides having an effect on bronchial vascularity, $\beta_{2}$ adrenergic agonists may attenuate vascular leakage induced by histamine, ${ }^{65}$ bradykinin ${ }^{66}$ and the platelet-activating factor. ${ }^{67}$

\section{Corticosteroids}

Inhaled corticosteroids (ICS) reduce airway wall vascularity in patients with asthma. ${ }^{68}{ }^{69}$ In addition, there are indications that higher doses of ICS may reverse the increased airway vascularity by reducing the expression of VEGF and angiogenic sprouts. ${ }^{70}$ This effect of ICS may be mediated by a reduced production of VEGF in structural and inflammatory cells. ${ }^{71}$

In two cross-sectional studies, $\Delta \mathrm{e}^{\circ} \mathrm{T}$ and $\mathrm{Q}_{\mathrm{aw}}$ were similar in corticosteroid-treated and untreated patients with asthma ${ }^{14}$ and COPD,$^{13}$, despite the efficacy of steroids in reducing bronchial blood flow. ${ }^{20}$ One hypothesis is that the vasoconstrictive action of ICS may have been balanced by $\beta_{2}$ agonist-induced vasodilation.

In contrast to the effect of chronic treatment with ICS, the acute inhalation of budesonide in patients with asthma causes a significant temporary reduction in $\mathrm{Q}_{\mathrm{aw}}$ which returns to baseline $1 \mathrm{~h}$ after inhalation. ${ }^{14}{ }^{39}$ ICS can potentiate the vasoconstrictor actions of norepinephrine and angiotensin II by upregulating their vascular receptors. ${ }^{72}$ Furthermore, corticosteroids may inhibit the synthesis of $\mathrm{NO},{ }^{73}$ thus causing vasoconstriction. In addition to these mechanisms of action, corticosteroids may also have a very rapid action ( $<5 \mathrm{~min}$ ) by inhibiting norepinephrine uptake in bronchial blood vessels. ${ }^{74}$

In contrast to asthma, the acute inhalation of budesonide is ineffective in lowering $\mathrm{O}_{\mathrm{aw}}$ in patients with COPD. ${ }^{13}$ The insensitivity of the bronchial circulation of patients with COPD to the inhalation of salbutamol and budesonide is confirmation that this group of patients has reduced vascular reactivity.

\section{Angiogenesis inhibitors}

Several inhibitors of angiogenesis have been studied in vitro and some have shown some promising clinical results in lung cancer, but these compounds have not yet been investigated in chronic lung disease. The therapeutic application of vascular growth factors may be promising. Ang-1 has been used to prevent or repair damaged and leaky vessels in diseases such as diabetic retinopathy, acute macular degeneration, ischaemia/reperfusion injury or in inflammation. The discovery of the molecular factors that regulate vessel formation may provide a number of new medications.

\section{VEGF inhibitors}

Different strategies have been devised to inhibit VEGF function. The injection of monoclonal VEGF antibodies into nude mice suppressed tumour growth and weight up to $96 \%,{ }^{75}$ and a recombinant humanised monoclonal antibody to VEGF (bevacizumab) has been shown to inhibit the growth of a variety of human cancer cell lines. ${ }^{76}$ The VEGF system can also be targeted through the inhibition of the VEGF receptor (VEGFR) using monoclonal antibodies or specific tyrosine kinase inhibitors. ${ }^{76}$

\section{Inhibitors of the Tie-angiopoietin system}

No ligand has so far been found for the Tie-1 receptor, whereas the angiopoietin family are the natural ligand for Tie- 2 . The activation of Tie- 2 by Ang-1 may be responsible for the assembly of the non-endothelial cells of the vessels, including perycites and smooth muscle cells. ${ }^{77}$ On the contrary, Ang-2 binds to the receptor Tie-2 without activating it and may therefore antagonise the action of Ang- 1 . The injection of the extravascular domain of the Tie- 2 receptor has been shown to reduce tumour growth by more than $75 \%$ in mice. ${ }^{78}$

\section{THERAPEUTIC IMPLICATIONS AND DIRECTIONS FOR FUTURE RESEARCH}

Even though our knowledge of the bronchial vasculatureparticularly in asthma-has been significantly improved in the last few years, the bronchial vessels in chronic inflammatory diseases such as COPD, interstitial lung disease and cystic fibrosis have not been sufficiently investigated. The lack of studies in these diseases is disappointing in view of the possible therapeutic implications that anti-angiogenic molecules may have. The role of the bronchial circulation in the absorption, distribution and action of medications is also unexplored, as is the action of anti-leukotrienes and theophylline.

The non-invasive measurement of bronchial blood flow has provided insights into the pathophysiology of the bronchial vasculature in airway disease, and has allowed a better understanding of the acute and chronic effect of medications. A clearer understanding of angiogenesis and of its role in diseases has led to the development of molecules with antiangiogenic properties which may be of benefit in the treatment of cancer. The development of more selective medications with fewer side effects may also prove beneficial for patients with chronic lung disease.

Competing interests: None.

\section{REFERENCES}

1. Deffebach ME, Charan NB, Lakshminarayan S, et al. The bronchial circulation. Am J Respir Crit Care Med 1987;135:463-81.

2. Charan NB, Turk GM, Dhand R. Gross and subgross anatomy of bronchial circulation in sheep. J Appl Physiol 1984;57:658-64.

3. Baile EM, Dahlby RW, Wiggs BR, et al. Effect of cold and warm dry air hyperventilation on canine airway blood flow. J Appl Physiol 1987;62:526-32.

4. Lung MA, Wang JC, Cheng KK. Bronchial circulation: an auto-perfusion method for assessing its vasomotor activity and the study of alpha- and beta-adrenoceptors in the bronchial artery. Life Sci 1976;19:577-80.

5. Saidel GM, Kruse KL, Primiano FPJ. Model simulation of heat and water transport dynamics in an airway. J Biomech Eng 1983;105:188-93.

6. Zapata-Ortiz V, Castro dlM, Fernandez E, et al. Bronchial circulation in high altitudes. Am J Physiol 1967:212:1464-8.

7. Long WM, Sprung CL, el Fawal H, et al. Effects of histamine on bronchial artery blood flow and bronchomotor tone. J Appl Physiol 1985;59:254-61.

8. Lakshminarayan S, Jindal SK, Kirk W, et al. Increases in bronchial blood flow following bronchoconstriction with methacholine and prostaglandin $\mathrm{F}_{2 \alpha}$ in dogs. Chest 1985:87:1835-45.

9. Warren RL, Powell WJ Jr. Acute alveolar hypoxia increases bronchopulmonary shunt flow in the dog. J Clin Invest 1986;77:1515-24.

10. Sasaki F, Pare P, Ernest D, et al. Endogenous nitric oxide influences acetylcholineinduced bronchovascular dilation in sheep. J Appl Physiol 1995;78:539-45.

11. Charan NB, Johnson SR, Lakshminarayan S, et al. Nitric oxide and beta-adrenergic agonist-induced bronchial arterial vasodilation. J Appl Physiol 1997;82:686-92.

12. Wagner EM, Foster WM. Importance of airway blood flow on particle clearance from the lung. J Appl Physiol 1996;81:1878-83. 
13. Paredi $\mathbf{P}$, Ward S, Cramer D, et al. Normal bronchial blood flow in COPD is unaffected by inhaled corticosteroids and correlates with exhaled nitric oxide. Chest 2007;131:1075-81.

14. Paredi P, Kharitonov SA, Barnes PJ. Correlation of exhaled breath temperature with bronchial blood flow in asthma. Respir Res 2005;6:15.

15. Wanner A, Barker JA, Long WM, et al. Measurement of airway mucosal perfusion and water volume with an inert soluble gas. J Appl Physiol 1988:65:264-71.

16. Cander L, Forster RE. Determination of pulmonary parenchymal tissue volume and pulmonary capillary blood flow in man. J Appl Physiol 1959;14:541-51.

17. Scuri M, McCaskill V, Chediak AD, et al. Measurement of airway mucosal blood flow with dimethylether: validation with microspheres. J App/ Physiol 1995;79:1386-90.

18. Brieva J, Wanner A. Adrenergic airway vascular smooth muscle responsiveness in healthy and asthmatic subjects. J Appl Physiol 2001;90:665-9.

19. Wanner A, Mendes ES, Atkins ND. A simplified noninvasive method to measure airway blood flow in humans. J Appl Physiol 2006;100:1674-8.

20. Brieva JL, Danta I, Wanner A. Effect of an inhaled glucocorticosteroid on airway mucosal blood flow in mild asthma. Am J Respir Crit Care Med 2000;161:293-6.

21. Chediak AD, Elsasser S, Csete ME, et al. Effect of histamine on tracheal mucosal perfusion, water content and airway smooth muscle in sheep. Respir Physiol 1991;84:231-43.

22. Clarke GW, Ledbetter CL, Greenway SD, et al. The effect of vasoactive substances on airway mucosal blood flow in asthma. Am J Respir Crit Care Med 2006;175:A457.

23. He H, Venema VJ, Gu X, et al. Vascular endothelial growth factor signals endothelial cell production of nitric oxide and prostacyclin through flk-1/KDR activation of c-Src. J Biol Chem 1999;274:25130-5

24. Gerber HP, Dixit V, Ferrara N. Vascular endothelial growth factor induces expression of the antiapoptotic proteins Bcl-2 and A1 in vascular endothelial cells. J Biol Chem 1998;273:13313-6.

25. Ferrara N. VEGF: an update on biological and therapeutic aspects. Curr Opin Biotechnol 2000;11:617-24.

26. Neufeld G, Cohen T, Gengrinovitch $S$, et al. Vascular endothelial growth factor (VEGF) and its receptors. FASEB J 1999:13:9-22.

27. Asai K, Kanazawa $\mathrm{H}$, Otani $\mathrm{K}$, et al. Imbalance between vascular endothelial growth factor and endostatin levels in induced sputum from asthmatic subjects. J Allergy Clin Immunol 2002;110:571-5

28. Feltis BN, Wignarajah D, Zheng L, et al. Increased vascular endothelial growth factor and receptors: relationship to angiogenesis in asthma. Am J Respir Crit Care Med 2006;173:1201-7.

29. Hoshino M, Takahashi M, Aoike N. Expression of vascular endothelial growth factor, basic fibroblast growth factor, and angiogenin immunoreactivity in asthmatic airways and its relationship to angiogenesis. J Allergy Clin Immunol 2001;107:295-301.

30. Kanazawa H, Asai K, Hirata K, Yoshikawa J. Possible effects of vascular endothelial growth factor in the pathogenesis of chronic obstructive pulmonary disease. Am J Med 2003;114:354-8

31. Thurston G, Suri C, Smith K, et al. Leakage-resistant blood vessels in mice transgenically overexpressing angiopoietin-1. Science 1999;286:2511-4

32. Leibovich SJ, Polverini PJ, Shepard HM, et al. Macrophage-induced angiogenesis is mediated by tumour necrosis factor-alpha. Nature 1987:329:630-2.

33. Carmeliet P. Mechanisms of angiogenesis and arteriogenesis. Nat Med 2000;6:389-95

34. Salvato G. Quantitative and morphological analysis of the vascular bed in bronchial biopsy specimens from asthmatic and non-asthmatic subjects. Thorax 2001;56:902-6.

35. Hashimoto $\mathbf{M}$, Tanaka $\mathrm{H}$, Abe S. Quantitative analysis of bronchial wall vascularity in the medium and small airways of patients with asthma and COPD. Chest 2005; 127:965-72.

36. Li $\mathbf{X}$, Wilson JW. Increased vascularity of the bronchial mucosa in mild asthma Am J Respir Crit Care Med 1997;156:229-33.

37. Barbato A, Turato G, Baraldo $\mathrm{S}$, et al. Epithelial damage and angiogenesis in the airways of children with asthma. Am J Respir Crit Care Med 2006:174:975-81.

38. Tanaka H, Yamada G, Saikai T, et al. Increased airway vascularity in newly diagnosed asthma using a high-magnification bronchovideoscope. Am J Respir Crit Care Med 2003:168:1495-9.

39. Kumar SD, Emery MJ, Atkins ND, et al. Airway mucosal blood flow in bronchial asthma. Am J Respir Crit Care Med 1998 1998;158:153-6.

40. Paredi $\mathbf{P}$, Kharitonov SA, Barnes PJ. Faster rise of exhaled breath temperature in asthma: a novel marker of airway inflammation? Am J Respir Crit Care Med 2001;165:181-4

41. Reid A, Heard BE. Preliminary studies of human pulmonary capillaries by India ink injection. Med Thorac 1962;19:215-9.

42. Cudkowicz L. The bronchial arteries in pulmonary emphysema. Thorax 1953:8:46-58.

43. Calabrese C, Bocchino V, Vatrella A, et al. Evidence of angiogenesis in bronchial biopsies of smokers with and without airway obstruction. Respir Med 2006:100:1415-22.

44. Hiroshima K, lyoda A, Shibuya K, et al. Evidence of neoangiogenesis and an increase in the number of proliferating cells within the bronchial epithelium of smokers. Cancer 2002;95:1539-45.

45. Kranenburg AR, de Boer WI, Alagappan VK, et al. Enhanced bronchial expression of vascular endothelial growth factor and receptors (Flk-1 and Flt-1) in patients with chronic obstructive pulmonary disease. Thorax 2005;60:106-13.

46. Rovina N, Papapetropoulos A, Kollintza A, et al. Vascular endothelial growth factor: an angiogenic factor reflecting airway inflammation in healthy smokers and in patients with bronchitis type of chronic obstructive pulmonary disease? Respir Res 2007;8:53.
47. Knox AJ, Stocks J, Sutcliffe A. Angiogenesis and vascular endothelial growth factor in COPD. Thorax 2005;60:88-9.

48. Nagai K, Betsuyaku T, Ito Y, et al. Decrease of vascular endothelial growth factor in macrophages from long-term smokers. Eur Respir J 2005;25:626-33.

49. Kasahara Y, Tuder RM, Taraseviciene-Stewart L, et al. Inhibition of VEGF receptors causes lung cell apoptosis and emphysema. J Clin Invest 2000:106:1311-9.

50. Liebow AA, Hales MR, Lindskog GE. Enlargement of the bronchial arteries and their anastomoses with the pulmonary arteries in bronchiectasis. Am J Pathol 2007:25:211-31.

51. Wagner HN Jr, Sabiston DC Jr, Lio M, et al. Regional pulmonary blood flow in man by radioisotope scanning. JAMA 1964:187:601-3.

52. Nagy JA, Vasile E, Feng D, et al. Vascular permeability factor/vascular endothelial growth factor induces lymphangiogenesis as well as angiogenesis. J Exp Med 2002;196:1497-506.

53. Peters KG, Kontos CD, Lin PC, et al. Functional significance of Tie2 signaling in the adult vasculature. Recent Prog Horm Res 2004:59:51-71.

54. Persson CG, Andersson M, Greiff L, et al. Airway permeability. Clin Exp Allergy 1995;25:807-14.

55. Nocker RE, Weller FR, Out TA, et al. A double-blind study on the effect of inhaled corticosteroids on plasma protein exudation in asthma. Am J Respir Crit Care Med 1999;159:1499-505.

56. Rennard SI, Basset G, Lecossier D, et al. Estimation of volume of epithelial lining fluid recovered by lavage using urea as marker of dilution. $J$ Appl Physiol 1986;60:532-8.

57. Kanazawa H, Nomura S, Asai K. Roles of angiopoietin-1 and angiopoietin-2 on airway microvascular permeability in asthmatic patients. Chest 2007;131:1035-41.

58. Kanazawa H, Nomura S, Yoshikawa J. Role of microvascular permeability on physiologic differences in asthma and eosinophilic bronchitis. Am J Respir Crit Care Med 2004;169:1125-30.

59. Van de Graaf EA, Out TA, Roos CM, et al. Respiratory membrane permeability and bronchial hyperreactivity in patients with stable asthma. Effects of therapy with inhaled steroids. Am Rev Respir Dis 1991;143:362-8.

60. Kanazawa H, Asai K, Hirata K, et al. Possible effects of vascular endothelial growth factor in the pathogenesis of chronic obstructive pulmonary disease. Am J Med 2003;114:354-8

61. Orsida $\mathbf{B E}$, Ward C, Li X, et al. Effect of a long-acting beta2-agonist over three months on airway wall vascular remodeling in asthma. Am J Respir Crit Care Med 2001; 164:117-21.

62. Koch AE, Polverini PJ, Kunkel SL, et al. Interleukin-8 as a macrophage-derived mediator of angiogenesis. Science 1992;258:1798-801

63. Ward C, Wang N, Zheng L, et al. Salmeterol reduces BAL IL8 levels in asthmatics on low dose inhaled corticosteroids. Eur Respir J 1998:11:P2520.

64. Wiesmann F, Petersen SE, Leeson PM, et al. Global impairment of brachial, carotid and aortic vascular function in young smokers: direct quantification by high-resolution magnetic resonance imaging. J Am Coll Cardiol 2004;44:2056-64.

65. Mirza ZN, Tokuyama K, Arakawa H, et al. Inhaled procaterol inhibits histamineinduced airflow obstruction and microvascular leakage in guinea-pig airways with allergic inflammation. Clin Exp Allergy 1998;28:644-52.

66. Advenier C, Oian Y, Koune JD, et al. Formoterol and salbutamol inhibit bradykininand histamine-induced airway microvascular leakage in guinea-pig. $\mathrm{Br} \mathrm{J}$ Pharmacol 1992;105:792-8.

67. Underwood SL, Lewis SA, Raeburn D. RP 58802B, a long-acting beta 2adrenoceptor agonist: assessment of antiasthma activity in the guinea-pig in vivo. Pulm Pharmacol 1992:5:203-12.

68. Orsida BE, Li X, Hickey B, et al. Vascularity in asthmatic airways: relation to inhaled steroid dose. Thorax 1999:54:289-95.

69. Chetta A, Zanini A, Foresi A, et al. Vascular endothelial growth factor up-regulation and bronchial wall remodelling in asthma. Clin Exp Allergy 2005;35:1437-42.

70. Feltis BN, Wignarajah D, Reid DW, et al. Effects of inhaled fluticasone on angiogenesis and vascular endothelial growth factor in asthma. Thorax 2007;62:314-9.

71. Horiuchi T, Weller PF. Expression of vascular endothelial growth factor by human eosinophils: upregulation by granulocyte macrophage colony-stimulating factor and interleukin-5. Am J Respir Cell Mol Biol 1997;17:70-7.

72. Ullian ME. The role of corticosteriods in the regulation of vascular tone. Cardiovas Res 1999;41:55-64.

73. Redington $\mathbf{A E}$, Meng $\mathrm{QH}$, Springall DR, et al. Increased expression of inducible nitric oxide synthase and cyclo-oxygenase-2 in the airway epithelium of asthmatic subjects and regulation by corticosteroid treatment. Thorax 2001;56:351-7.

74. Horvath G, Lieb T, Conner GE, et al. Steroid sensitivity of norepinephrine uptake by human bronchial arterial and rabbit aortic smooth muscle cells. Am J Respir Cell Mol Biol 2001;25:500-6.

75. Kim KJ, Li B, Winer J, et al. Inhibition of vascular endothelial growth factor-induced angiogenesis suppresses tumour growth in vivo. Nature 1993;362:841-4

76. Shepherd FA, Sridhar SS. Angiogenesis inhibitors under study for the treatment of lung cancer. Lung Cancer 2003;41(Suppl 1):S63-72.

77. Suri C, Jones PF, Patan S, et al. Requisite role of angiopoietin-1, a ligand for the TIE2 receptor, during embryonic angiogenesis. Cell 1996:87:1171-80.

78. Lin $\mathbf{P}$, Polverini $\mathbf{P}$, Dewhirst $\mathrm{M}$, et al. Inhibition of tumor angiogenesis using a soluble receptor establishes a role for Tie2 in pathologic vascular growth. J Clin Invest 1997; 100:2072 